\title{
Current Account Balances, External Debts and Exchange Rates in Selected African Countries
}

\author{
Ohiomoje Abubakar Iyemifokhae \\ Department of Economics, School of Economics, \\ University of Ibadan, Ibadan, Oyo State, Nigeria.
}

Keywords

Current Account Balances, External Debts, Exchange Rates, Generalised Method of Moments, Instruments.

\begin{abstract}
s
Most African countries had been bedeviled by the problem of deficits in their current account balances (World Bank, 2020). In a bid to overcome this challenge, they usually resorted to contracting external debts from institutions and countries that required them to repay these loans in the currencies of the creditors. Thus, the rate of exchange between the creditors and debtors should be of concern. Several studies have been carried out to examine the relationship between current account balances, external debts and the exchange rates. Some studies found a unidirectional relationship among these variables. In some other studies, the relationship knitting these variables was bi-directional. In most of these studies, the methods of analysis ranged from the ordinary least squares, panel data analysis and the vector error correction model. This study fills the gap in the literature by examining the relationship across these variables making use of the generalized methods of moments (GMM). The GMM estimation technique will correct for unobserved heterogeneity, endogeneity and measurement errors which were observed in the data. The study found that a $9.46 \%$ increase in external debts leads to a percentage increase in current account balances in the selected African countries. Also, there is a positive and significant relationship between the exchange rates and the current account balances in the group.
\end{abstract}

\section{Introduction}

The difference between the export and import of goods and services is known as the current account balances. When the exports of a country surpass her imports, this is current account deficits. Here, such a country is buying more from foreigners than it sells to them, and the former country must search for ways to finance this deficit. A country has a current account surplus when its exports exceed her imports. Such a country sells more goods to foreigners than it buys from them. In this case, the former country lends its surplus to foreigners. In deficit financing, the sources of borrowings could take the form of bond finance, bank finance, official lending (from institutions like International Monetary Fund, African Development Bank), foreign direct investment and portfolio investment in the ownership of firms. These sources of financing can be in the form of debt or equity finance. When a country's liabilities are knitted in debt, its scheduled repayments to creditors do not fall if her income falls. It carries fixed repayment structure. In equity financing, creditors are considered to be shareholders and share in the good or bad times of debtors (Aigbokan, 1991). When a country incurs debts outside its geographical boundary to finance her deficits, this is termed external debts. The repayments of such debts are overwhelmingly denominated in foreign currencies (usually in the currency of the creditor nation or where the credit institution is domiciled). Lending institutions from the developed countries do not want to be overwhelmed, given the high rate of devaluation and inflation that thrive in developing economies. Thus, such institutions usually insist that debtors from developing countries repay them in lenders' own currencies (Mike, 2012). Economists like Barry Eichengreen of the California University and Berkeley and Richardo of Harvard University described the phenomenon in which developing countries cannot borrow in their own currencies as original sin. Other economists argue that the sin of developing countries is not original but stems from their antecedents of ill-advised economic policies. The debate is far from being over. The inference drawn 
from these arguments is that the rates of exchange between countries need to be examined side by side with macroeconomic variables. This study limits itself, however, to the current account balances, external debts and exchange rate in selected countries in Africa.

In 1979, the Federal Reserve Bank in the United States (US) adopted tight inflationary policies that pushed the global economy into recession. This made it difficult for underdeveloped countries to meet their prior debt obligations that were denominated in the US dollar. For instance, Mexico raised an alarm that its central bank was running out of foreign reserves and that the country could not repay its foreign debts. Given the similarities between Mexico and other Latin American countries, creditors (in developed countries) started to hedge their risks by reducing credits and demanded for the repayments of their existing loans from debtor countries and institutions. The underlying problem that the creditors envisaged is that, given the high rate of inflation and devaluation (of local currencies) that characterized the economies of developing and emerging countries, most of these debtor nations could not obtain favorable trade balances to offset their external debts. This problem did not rescind until 1989 when the United States, while trying to avert impending political instability, insisted that American banks granted some debt reliefs to indebted developing countries. The early 90s saw the resurgence of private capital flows into developing countries. Many developing countries relied on financial inflows to finance domestic investments and built their inadequate infrastructures. At the end of 2007, developing countries had accumulated external debt to the tune of $\$ 3.5$ trillion (World Bank, 2020). Since these external debts had to be repaid in the currencies of creditor nations and institutions, indebted developing countries ought to be concerned about their respective countries' exchange rates and current account balances. This was what informed the decisions of researchers to examine the economic relationship among these variables.

Several studies have been carried out on the relationship between external debts, current account balances and the exchange rates. Some studies found that there were causalities on this relationship. In some other studies, the relationship was bi-directional; that is, moving from current account balances to external debts and exchange rate and drifting back from exchange rate via external debts and to current account balances. In other words, the relationship guiding these three variables was not a uni-directional one. This study will examine this relationship with special interest in the selected countries in Africa.

Furthermore, in most of the earlier studies of the subject matter, the method of analyses ranged from the ordinary least square techniques in which endogeneity would be a major concern to the Vector Error Correction model, Panel Data analysis and the Autoregressive Distributed Lag (Fratzscher and Samo, 2010; Rehman and Rehman, 2010; Taoufik, 2019; Oyakhilome, 2018; David and Olohitare, 2013; James and Kennedy, 2018). This study will fill the vacuum in the literature by making use of the Generalised Method of Moments (GMM) in its analysis.

\section{Background of the Study}

It has been observed that the current account balances of most developing countries (like those considered for this study) had hitherto been on deficits. The value of imports purchased from their trading partners exceeded those of exports. This has been the trend in several decades. The graph below gives a representation of the current account balances of the selected countries in Africa. 

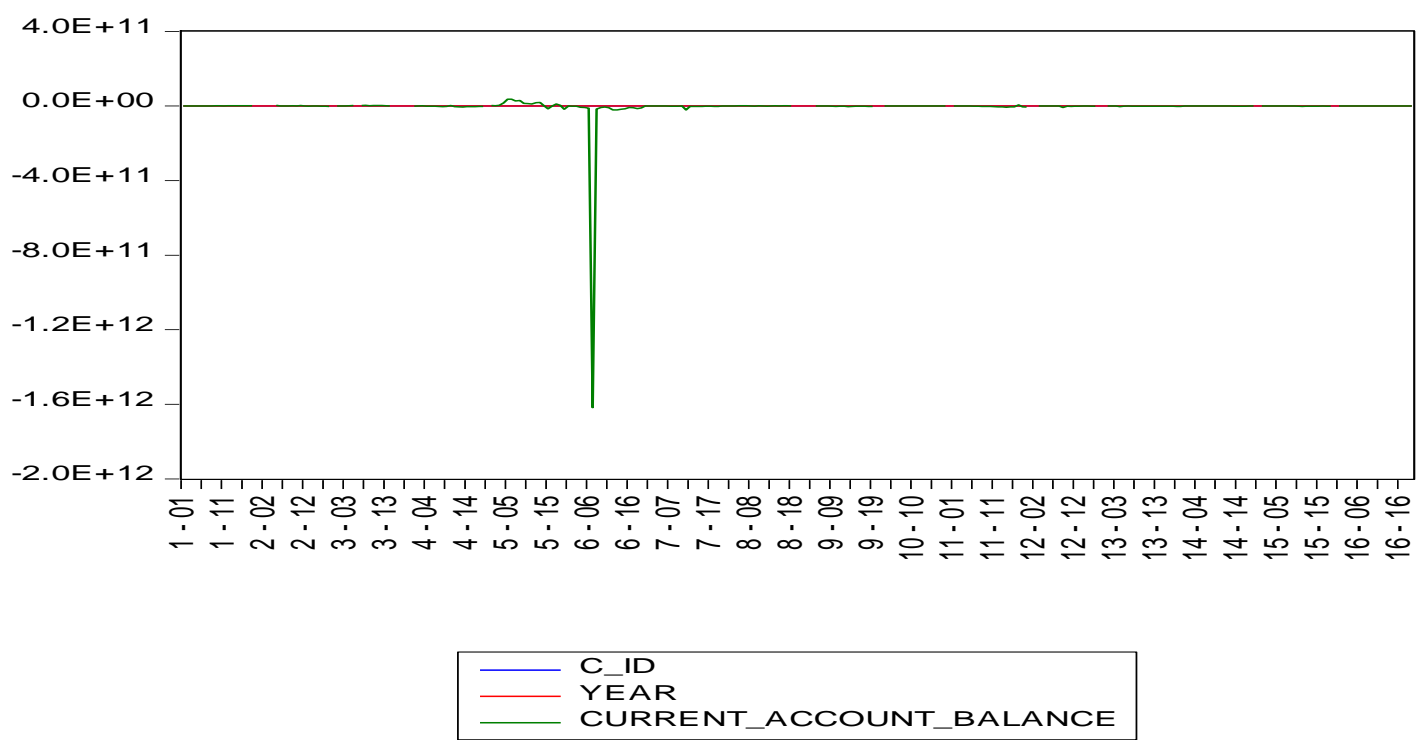

Figure 1. Current Account Balances in the Selected Countries.

Source: Author's Computations.

The $x$-axis represents the countries identifications (C_ID) and the years in consideration (2001-2019) while the y-axis shows the current account balances of the group. In the graph, the current account balances of the selected African countries were predominantly on deficits in most of the sample period. Apart from the country with C_ID 5 (Nigeria) that recorded some current account surpluses in few years, there was hardly a semblance of this in the group.

The volume of external debts contracted by developing countries had been high during the sample period. This metamorphosed from the fact that it was exigent for these countries to uplift their infrastructures to boost their productive capacity and the desideratum for such countries to be competitive in the international market. The figure 2 gives a diagrammatic representation of the size of external debts of the selected countries over the period under review.
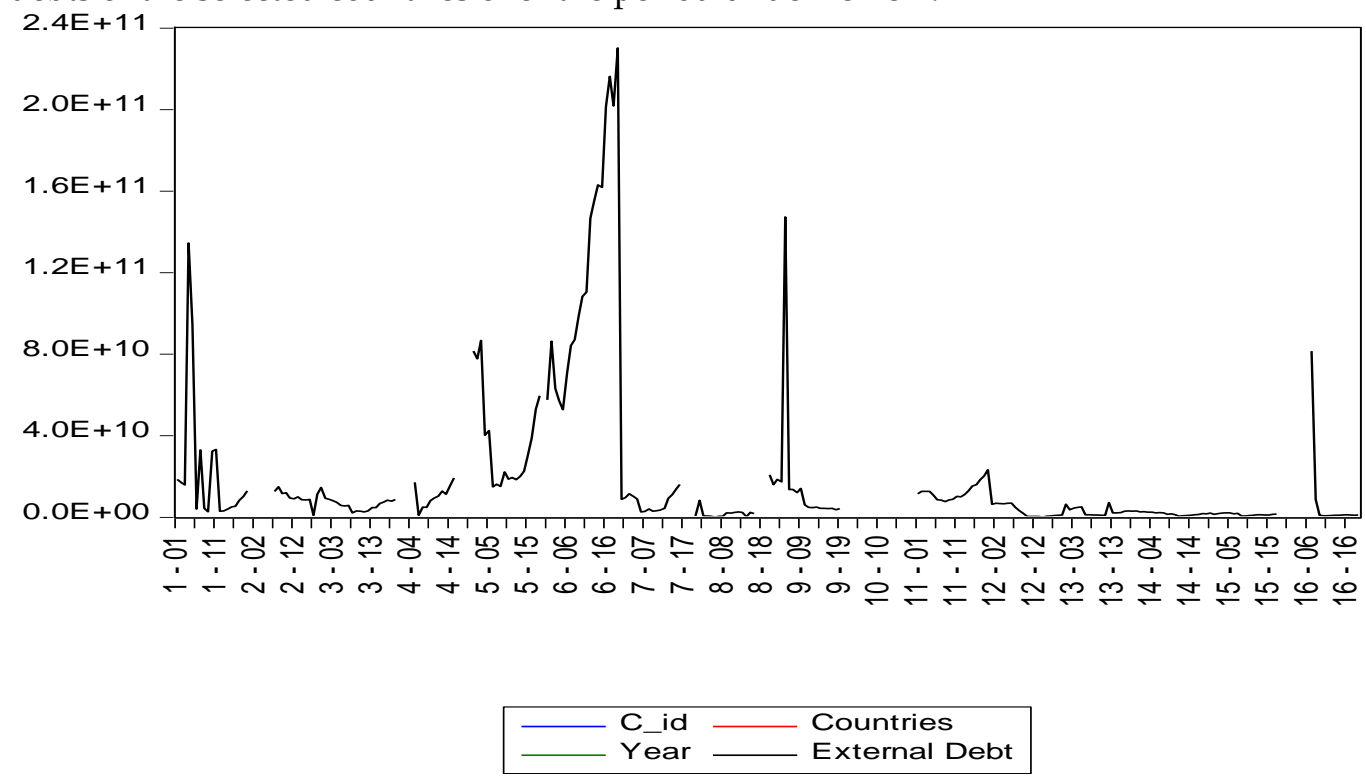

Figure 2. External Debts of the Selected African Countries.

Source: Author's Computation. 
It can be seen from the figure above that there had been volatilities in the size of external debts contracted by the selected African countries in the sample period. The number of external debts rose to almost \$3 trillion in 2016. Although, there were periods when the tides of external debts were in their minimum, the graphical representation showed that members of this group of selected countries had been engaged strongly in different volumes of external debts in the periods under consideration (2001 - 2019).

The Figure 3 shows the exchange rates of the selected African countries over the sample period. The exchange rates of this set of indebted African countries had been very low relative to the currencies of institutions and countries that stood as creditors to the debts. In Figure 3, there were periods of break, suggesting that data on exchange rates were omitted in some countries (in the group) in certain number of years.

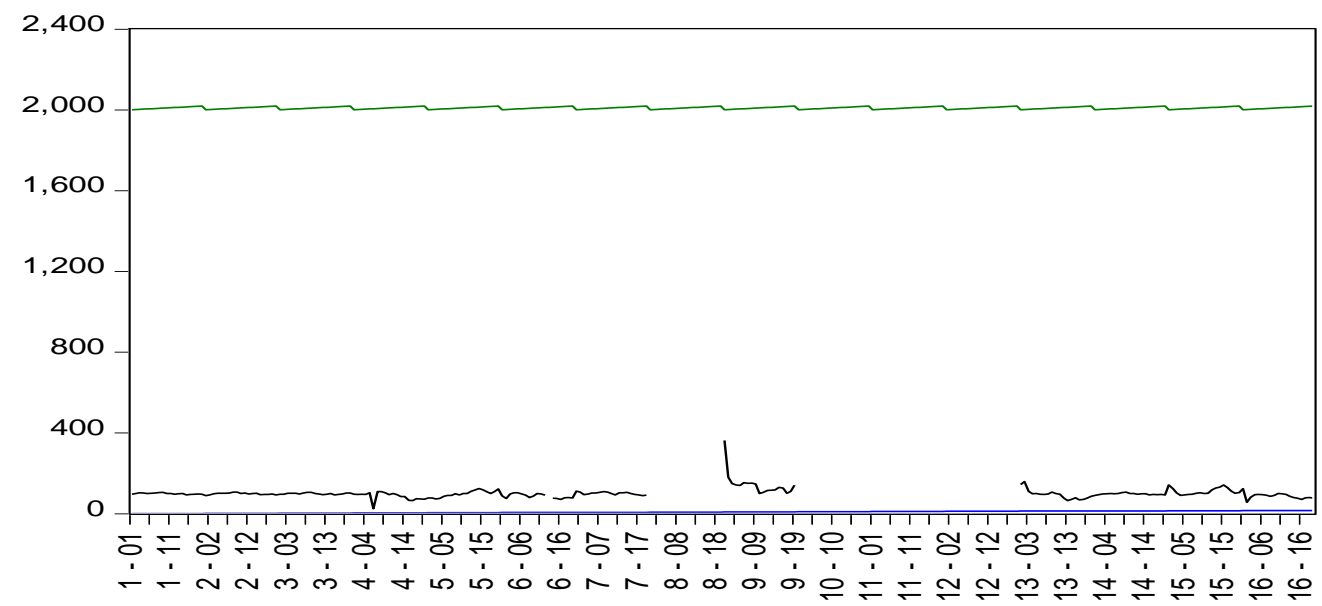

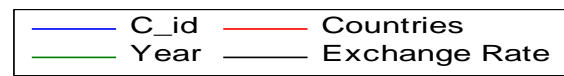

Figure 3. The Exchange Rates of the Selected African Countries.

Source: Author's Computation.

\section{Literature Review}

Several studies had been conducted on the relationship between current account balances and external debts. In few other instances, exchange rates were included in the framework. For instance, James and Kennedy (2018) examined the relationship between external debt servicing and current account balances in Kenya. The study found that external debt servicing granger caused current account balances in Kenya. The exchange rate variable was not inclusive, and the emphasis of the study was on Kenya. Similarly, Oyakhilome (2018) carried out a study on external debts and current account adjustments (with a focus on the role of trade openness) in Sub Saharan Africa. The study discovered that external debts were significantly responsible for the variations in trade openness in the region. David and Olohitare (2013) examined exchange rate misalignments and balance of payment adjustments in Nigeria. Apart from the fact that the study placed its search light exclusively on Nigeria, the data used (between 1973 and 2012) was not contemporaneous with recent happenings in respect to the considered variables.

Besides, the methodologies adopted by most of the literature ranged from the vector error correction model (James and Kennedy, 2018; David and Olohitare, 2013)) to panel data analysis (Oyakhilome, 2018). This research shall fill the gap in literature by examining (in a single study) the relationship of current account balances, external debts and exchange rate in sixteen countries in Sub Saharan Africa. Furthermore, the GMM technique is used (in this study) to estimate the relevant variables because of the peculiarities of the data. This technique will help to solve the problems of unobserved heterogeneity, endogeneity and measurement errors (Arrelano and Bond, 1991). 


\section{Methodology \\ 4.1 Model Specification}

On the stationarity or otherwise of the variables in the model, the Levin, Lin and Chu $\mathrm{t}^{\star}$ unit root tests were conducted. The tests showed that the probability value (at intercept and trend) of the variables fell below $5 \%$. This proved that the null hypothesis that stated that the series were stationary should be rejected for the alternative hypothesis that indicated the presence of unit roots in the variables in the model. First differencing the series did not alter the probability outcome. It still fell below 5\%. This indicated that there was heterogeneity in the data set. Given this shortcoming, the study adopted the Generalised Methods of Moments (GMM) to control for endogeneity of the lagged dependent variables, unobserved panel heterogeneity and measurement errors in the data. The basis of method of moments is that given certain sets of assumptions, a sample statistic will converge in probability to some constant. The constant is a function of the unknown parameter of the distribution. Let us consider the independent identically random sampling from a distribution as $\mathrm{f}\left(\mathrm{y} \mid \vartheta_{1}, \ldots \ldots \ldots \ldots \ldots . ., \vartheta_{\mathrm{k}}\right)$ with finite moments of $E\left[y_{i}^{k}\right]$. The sample consists of $n$ observations which are given as $y_{1}, \ldots \ldots, y_{\mathrm{n}}$. The kth moment is

$$
\mathrm{M}_{\mathrm{k}}=\frac{1}{n} \sum_{i=1}^{n} Y_{i}^{k}
$$

\section{(Given that $\mathrm{E}\left[\mathrm{M}_{\mathrm{k}}\right]=\mu_{\mathrm{k}}=\mathrm{E}\left[\left[Y_{i}^{k}\right]\right.$ )}

It is argued that each sample statistics has a counterpart in the population. For example, there is a correspondence between the sample mean and the population expected value (Khinechine Theorem). $\mu_{\mathrm{k}}$ is the mean of the $K^{\text {th }}$ parameter which is the sample mean while $\mathrm{E}\left[\left[Y_{i}^{k}\right]\right.$ is the expected value of the population. By convention, the variance of the Kth moment is

$$
\operatorname{Var} \mathrm{M}_{\mathrm{k}}^{\prime}=\frac{1}{n} \operatorname{Var}\left[Y_{i}^{k}\right]=\frac{1}{n}\left[\mu_{2 k}^{r}-\mu_{k}^{\prime 2}\right]
$$

The Lindberg-Levy Central Limit Theorem states that

$$
\sqrt{n}\left(M_{k}^{v}-\mu_{k}^{s}\right) \stackrel{d}{\rightarrow} \mathrm{N}\left[0 \mu_{2 k}^{s}-\mu_{k}^{r 2}\right]
$$

By computing $K$ raw moments and equating them to these functions, $K$ equations are obtained that can be used to provide estimates for the Kth unknown parameters.

The GMM estimator is based on the set of population orthogonality conditions.

$$
\mathrm{E}\left[\mathrm{M}_{\mathrm{i}}\left(\theta_{0}\right)\right]=0
$$

Where $\theta_{0}$ denotes the vector of the true parameter. The subscripts $i$ on the term refers to dependence on the observed data $Y_{\mathrm{i}}, X_{\mathrm{i}}, A_{\mathrm{i}}$ and $Z_{\mathrm{i}}$. Let current account balances be represented by $Y_{\mathrm{i}}$, external debt be denoted by $X_{\mathrm{i}}$ and exchange rate, $A_{\mathrm{i}}$. The vector $Z_{\mathrm{i}}$ is the instruments. The moment is a set of $L$ equations involving the $k$ parameters. It is assumed that the sample converges to these parameters. Averaging $i$ over the sample observations generates the sample moment equation.

$$
\mathrm{E}\left[\mathrm{M}_{\mathrm{n}}\left(\theta_{0}\right)\right]=0
$$

Where $\mathrm{M}_{\mathrm{n}}\left(\theta_{0}\right)=\frac{1}{n} \sum_{i=1}^{n} M_{i}\left(\theta_{0}\right)$

Let us consider empirical moment equations which define the instrumental variable estimator for a linear or non-linear regression model as

$$
\mathrm{E}[\mathrm{Mi}(\beta)]=\mathrm{E}\left[\frac{1}{n} \sum_{i=1}^{n} z_{i}\left(\mathrm{y}_{\mathrm{i}}-\mathrm{h}\left(\mathrm{x}_{\mathrm{i}}, \mathrm{a}_{\mathrm{i}}, \beta\right)\right]=0 .\right.
$$

In equation (6), there are $L$ instrumental variables in $z$ and $k$ parameter in $\beta$. These define $L$ moment equations, one for each instrumental variable. For there to be convergence of the sample parameters with those of the population, certain assumptions must hold.

The conditional mean function $h\left(\mathrm{x}_{\mathrm{i}}, \mathrm{a}_{\mathrm{i}}, \beta\right)$ is a continuous function of $\beta$, although not necessarily of $x$ and $a$. Given this assumption, we may assume that the derivative of the moments converges to a 


$$
\mathrm{G}_{\mathrm{n}}\left(\theta_{0}\right)=\frac{\partial M_{0}\left(\theta_{0}\right)}{\partial \theta_{0}^{2}}=\frac{1}{n} \sum_{i=1}^{n} \frac{\partial M_{i n}\left(\theta_{0}\right)}{\partial \theta_{0}^{2}}
$$

probability limit $G_{\mathrm{n}}\left(\theta_{0}\right)=G\left(\theta_{0}\right)$. The continuity assumption and its derivative enable us to invoke the Slutsky Theorem for time series data.

Another assumption is that the number of moment conditions is at least as large as the parameter. This implies that $L \geq K$.

Thirdly, the number of rows $\geq$ number of columns (in its matrix)

It is also assumed that the moments have a finite asymptotic covariance matrix $(1 / n) \emptyset$.

In this study, the specification of the variables was adopted similar to the framework of Dahlberg and Johansson (2000) which estimated local government expenditures of hundreds of municipal councils in Sweden. The model for this study took this form:

$$
\mathrm{Y}_{\mathrm{ij}}=\mathrm{a}_{\mathrm{i}}+\sum_{i=1}^{m} \beta_{\mathrm{j}} \mathrm{Y}_{\mathrm{ij}-1}+\sum_{i=1}^{m} \rho_{\mathrm{j}} \mathrm{X}_{\mathrm{ij}-1}+\sum_{i=1}^{m} \delta_{\mathrm{ij}} \mathrm{A}_{\mathrm{ij}-1}+\mathrm{f}_{\mathrm{i}}+\varepsilon_{\mathrm{it}}
$$

For $i=1, \ldots \ldots \ldots, n ; \mathrm{t}=m+1, \ldots \ldots \ldots, 19$. Equation (8) contained a specific effect, $f_{i}$, which was not stated to be fixed or random. To eliminate the individual effect, the model was converted to first differences (see Greene, 2008) which produced the equation (9)

$$
\Delta \mathrm{Y}_{\mathrm{ij}}=\mathrm{a}_{\mathrm{i}}+\sum_{i=1}^{m} \beta_{\mathrm{j}} \Delta \mathrm{Y}_{\mathrm{ij}-1}+\sum_{i=1}^{m} \rho_{\mathrm{j}} \Delta \mathrm{X}_{\mathrm{ij}-1}+\sum_{i=1}^{m} \delta_{\mathrm{ij}} \Delta \mathrm{A}_{\mathrm{ij}-1}+u_{\mathrm{it}}
$$

Where $\Delta \mathrm{Y}_{\mathrm{ij}}=\mathrm{Y}_{\mathrm{ij}}-\mathrm{Y}_{\mathrm{ij}-1} ; \Delta \mathrm{X}_{\mathrm{ij}}=\mathrm{X}_{\mathrm{ij}}-\mathrm{X}_{\mathrm{ij}-1} ;$ and $\Delta \mathrm{A}_{\mathrm{ij}}=\mathrm{A}_{\mathrm{ij}}-\mathrm{A}_{\mathrm{ij}-1}$

The orthogonality conditions were given as

$$
\mathrm{E}\left[Z_{i}^{v} \mathrm{ui}\right]=0 \text {. }
$$

Where $u_{\mathrm{i}}$ was the vector of error term.

\subsection{The Variables Measurement and Methodology}

The variables used in this study are the current account balances, external debts and exchange rate of the selected African countries. The dependent variable, current account balances, is regressed against the endogenous variables of external debts and exchange rates of the sampled countries, given some instruments. There is also the stochastic term that will take care of unobserved characteristics in the model. Thus, the variables of the model of this study are spelt out in the following format.

$$
\mathrm{Y}_{\mathrm{ij}}=\mathrm{a}_{\mathrm{i}}+\sum_{i=1}^{m} \beta_{\mathrm{j}} \mathrm{Y}_{\mathrm{ij}-1}+\sum_{i=1}^{m} \rho_{\mathrm{j}} \mathrm{X}_{\mathrm{ij}-1}+\sum_{i=1}^{m} \delta_{\mathrm{ij}} \mathrm{A}_{\mathrm{ij}-1}+\mathrm{f}_{\mathrm{i}}+\varepsilon_{\mathrm{it}}
$$

Current account balances are represented by $Y_{i}$, external debt is denoted by $X_{i}$ whilst exchange rate is given as $A_{\mathrm{i}}$. The vector $Z_{\mathrm{i}}$ is the instruments. Let us consider empirical moment equations which define the instrumental variable estimator as:

$$
\mathrm{E}[\mathrm{Mi}(\beta)]=\mathrm{E}\left[\frac{1}{n} \sum_{i=1}^{n} z_{i}\left(\mathrm{y}_{\mathrm{i}}-\mathrm{h}\left(\mathrm{x}_{\mathrm{i}}, \mathrm{a}_{\mathrm{i}}, \beta\right)\right]=0\right.
$$

In equation (12), there are $N$ instrumental variables in $z$ and $k$ parameter in $\beta$. These define $N$ moment equations, one for each instrumental variable. For there to be convergence of the sample parameters with those of the population, certain assumptions must hold. The orthogonality condition was given as

$$
\mathrm{E}\left[Z_{i}^{\prime} \text { ui }\right]=0
$$

Where $u_{\mathrm{i}}$ was the vector of error term.

\subsection{Data}

The data was obtained from the World Bank Development Indicators. The data covered selected African countries of Angola, Benin, Cameroon, Congo Democratic Republic, Cote d'Voire, Gabon, Ghana, Lesotho, Liberia, Kenya, Malawi, Nigeria, Sierra Leone, South Africa, Togo and Uganda. The dataset was between 2001 and 2019. The data was analysed using Eviews.

\section{Results and Discussions}

The Arrelano-Bond Serial Correlation Test was conducted on the series and the outcome estimate gave a probability value of $69.25 \%$ which was greater than $5 \%$. This implied that the study should accept the null hypothesis which stated that there was no serial correlation in the series. Given that Panel data 
analysis placed much emphasis on group data rather than the information available in the individual countries, the findings of the summary statistics showed that current account balances in all the selected countries had a mean value of $-6.21 \mathrm{E}+09$, external debt averaged $1.88 \mathrm{E}+10$ while exchange rate in the group had a mean value of 100.83 to the US dollar. The standard deviation for current account balances, external debts and exchange rate were $9.73 \mathrm{E}+10,3.81 \mathrm{E}+10$ and 25.24 respectively. These were the average measures of scores (current account balances, external debts and exchange rates) from their respective mean values in the group. The current account balances of the selected African countries were negatively skewed as the mean value $(-6.21 \mathrm{E}+09)$ was lesser than that of the median $(-1.84 \mathrm{E}+08)$. However, external debts and exchange rates were positively skewed, given that their respective mean values $(1.88 \mathrm{E}+10$ and 100.8) were greater than those of their median (5.70E+09 and 99.1). In sum, the distribution of the sample was not normally distributed, and this was corroborated by the probability of Jarque Bera which was less than $5 \%$.

When we estimated the data based on equation (8) in which the model contained specific effects, the result of the generalized method of moments (GMM) showed that about a $1 \%$ increase in current account balance brought about $35.5 \%$ decline in external debts in the group of selected African countries. This result was not watertight as the probability level was beyond the $5 \%$ significant level. Similarly, an inverse relationship was also seen between current account balances and exchange rates, but the result could not be reported because it was insignificant. Given these shortcomings, the model was first differenced to remove the individual effects.

Also, relevant instruments were incorporated in the model in order to take care of unobserved heterogeneity, endogeneity and measurement error in the data set. The transformed model of equation (9), after first differencing, generated a GMM estimates that deciphered the relationships of current account balances, external debts and exchange rates. It could be seen from the result that among the list of included instruments was lag 2 of current account balances. This, in other words, meant that this particular instrument was internal, and it was incorporated to take care of endogeneity arising from this particular variable with the residual.

From the GMM estimates, a unit increase in current account balances in the current period led to a decline of $11.58 \%$ in the balances in the previous time or period. This estimate was significant at less than $5 \%$ level. Intuitively, this means that in the selected African countries, a fall in the current account balances in the previous time or lag 1 by $11.58 \%$ results to a percentage increase in the balances in the present period. This suggests that the net balances in the current account today (in the group) is negatively and significantly related with the values of the previous time. The current account balances or equilibrates when receipts are equal to payments or exports are equal to imports. However, this rarely exists in practice. The current account is in surplus or positive if exports exceed imports. It falls into deficit or negative when the reverse is the case. Interpreting the result of an $11.58 \%$ decline in current account balances in lag 1 means that a drift in the gap between import and exports by $11.58 \%$ in the immediate past period generates a unit increase in the gap between exports and import in the current period in this group of selected African countries.

A $9.46 \%$ increase in external debts in the selected African countries led to a percentage increase in the current account balances in the group. This implied that if the quantum of debts contracted by the selected countries rose by $9.46 \%$, the value of exports surpassed that of imports by a percentage in the group. This result was significant at less than $5 \%$ significant level. Thus, there was direct relationship between current account balances and external debt in the selected African countries. This outcome aligns with theoretical expectations. Most of the economies of the selected African countries are emerging. Ideally, these economies are driven by the need to boost productive capacity if they contract external debts. Quite often than not, the debts are put into the development of infrastructures and to improve the technical knowhow of these economies. It is, therefore, expected that as the volume of these debts' soars, domestic capacity and export should move northward. This is strongly responsible for the positive relationship between external debts and current account balances in these selected countries. 
There was positive and significant relationship between current account balances and the exchange rate. A percentage increase in the exchange rate led to $6.02 \mathrm{E}+08$ variation in the current account balances in the selected African countries. This result was significant at less than $5 \%$ level of significance. Favorable current account balances (a situation where export is greater than import) engender improvements in the exchange rate between a concern and its trading partners. It is this sequence of events that was reflected in the GMM estimates of the relationship between current account balances and the exchange rate in the selected African countries.

\subsection{Conclusion}

The selected countries in Sub Saharan Africa should endeavor to boost their productive capacity and ensure that their products are competitive in the international market if they are to encounter improvements in their exchange rate. This, in turn, will put these countries in a better position when they are repaying their debt obligations to their external creditors as they would have earned more foreign reserves from the growth in exports. This is affirmed by the result of this study which discovered that there was positive relationship between current account balances and the exchange rate in this group of countries in Sub Saharan Africa.

Also, these countries should be cautious when contracting external debts as this study discovered that when these debts rose by $9.46 \%$, exports exceeded imports by a unit. These statistics insinuated that external debts were very fundamental in jump-starting growth in these economies. The growth in external debts should be in double digits for the selected countries to actualize favorable current account balances. The inference drawn from these statistics is that there are infrastructural decay and relatively lower receipts from exports in the sample countries. Ideally, external debts should be put to judicious use, especially on the development of critical infrastructures that will ensure that manufacturers operate at full capacity and exports are promoted. There is also the need to strengthen institutions that ensure proper monitoring of the appropriation of external debts in the recipient countries.

\subsection{Limitation of the Study}

The study was faced with the challenge of omitted observations in some of the selected African countries.

\section{References}

Aigbokan, Ben (1991).The Naira Exchange Rate Depreciation and Domestic Inflation. The India Journal of Economics, Vol. LXXI, Part IV, No. 283.

Arellano, M. and Bond, S. (1991). Some Tests of Specification for Panel Data: Monte Carlo Evidence and Application to Employment Equations. The Review of Economic Studies.

Dahlberg, M. and Johansson, E. (2010). An Examination of the Dynamic Behavior of Local Governments using GMM bootsrapping Methods. Journal of Applied Econometrics, 15 (4): 401-416.

David, U. and Olohitare O. (2013). Exchange Rate Misalignment and Balance of Payment Adjustments in Nigeria. European Scientific Journal, Volume 9 (13).

Fratzscher M, and Sarno, L. (2010). Asset Prices, Exchange Rates and the Current Account, SSRN Electronic Journal 54 (5): 643-658.

Greene, W. (2008). Econometric Analysis, $6^{\text {th }}$ Edition, New Jersey, Pearson-Prentice Hall.

James M., Kennedy, N. (2018). External Debt Servicing and Current Account Balance in Kenya. International Journal of Development and Sustainability, Volume 7(5): 1688-1710.

Mike, Obadan (2012). Foreign Exchange Market and the Balance of Payments: Elements, Policies and the Nigerian Experience. Goldmark Press Limited, Benin City, Nigeria.

Oyakhilome, Ibhagul (2018). External Debt and Current Account Adjustments: The Role of Trade Openness, Cogent Economics and Finance (2018), 16: 1446247.

Rehman, R. and Rehman, A. (2010). Causal Relationship between Macroeconomic Variable and Exchange Rate, International Research Journal of Finance and Economics, 46: 58-62.

Taoufik Bouraoui, 2019, External Debt, Current Account Balance and Exchange Rate in Emerging Countries. Economics Bulletin, Access Econs, Volume 39 (4): 2333-2342.

World bank (2020), World Bank Indicator Database. 
Table 1. Arellano-Bond Serial Correlation Test

\begin{tabular}{lllll}
\hline \hline Test order & m-Statistic & rho & SE(rho) & Prob. \\
\hline \hline & & - & \\
& & 200681670549 & \\
& & 057240000000 & NA \\
AR(1) & NA & 0 & NA & \\
& & -312565849186790349214055 \\
AR(2) & -0.395478 & 1118800000001366400000000.6925 \\
\end{tabular}

Source: Author's Computation.

Table 2. GMM Regression based on Equation 8 (with Specific Effects)

Dependent Variable: CURRENT_ACCOUNT_BALANCE

Sample (adjusted): 20022019

Periods included: 18

Cross-sections included: 12

Total panel (unbalanced) observations: 174

2SLS instrument weighting matrix

Instrument specification: C CURRENT_ACCOUNT_BALANCE(-1)

EXTERNAL_DEBT(-1) EXCHANGE_RATE(-1)

Constant added to instrument list

\begin{tabular}{lllll}
\hline \hline Variable & Coefficient & Std. Error & t-Statistic & Prob. \\
\hline \hline EXTERNAL_DEBT & -0.354898 & 0.247008 & -1.436786 & 0.1526 \\
EXCHANGE_RATE & -23017018 & $1.03 \mathrm{E}+08$ & -0.222443 & 0.8242 \\
\hline \hline R-squared & 0.017795 & Mean dependent var & $-9.27 \mathrm{E}+09$ \\
Adjusted R-squared & 0.012085 & S.D. dependent var & $1.23 \mathrm{E}+11$ \\
S.E. of regression & $1.22 \mathrm{E}+11$ & Sum squared resid & $2.56 \mathrm{E}+24$ \\
Durbin-Watson stat & 2.165293 & J-statistic & 0.087897 \\
Instrument rank & 4 & Prob (J-statistic) & 0.957003 \\
\hline \hline
\end{tabular}


Table 3. GMM Regression after Transformation (Equation 9)

Dependent Variable: CURRENT_ACCOUNT_BALANCE

Method: Panel Generalized Method of Moments

Transformation: First Differences

Sample (adjusted): 2003 - 2019

Periods included: 17

Cross-sections included: 12

Total panel (unbalanced) observations: 162

White period instrument weighting matrix

White period standard errors \& covariance (d.f. corrected)

Instrument specification: @DYN(CURRENT_ACCOUNT_BALANCE,-2)

EXTERNAL_DEBT(-1) EXCHANGE_RATE(-1)

Constant added to instrument list

\begin{tabular}{|c|c|c|c|c|}
\hline Variable & Coefficient & Std. Error & $\mathrm{t}$-Statistic & Prob. \\
\hline CURRENT_ACCOUNT_BALANCE(-1) & -0.115795 & 0.000433 & -267.6729 & 0.0000 \\
\hline EXTERNAL_DEBT & 0.094557 & 0.000477 & 198.1833 & 0.0000 \\
\hline EXCHANGE_RATE & $6.02 \mathrm{E}+08$ & 9505460 & 63.32898 & 0.0000 \\
\hline \multicolumn{5}{|c|}{ Effects Specification } \\
\hline \multicolumn{5}{|l|}{ Cross-section fixed (first differences) } \\
\hline Mean dependent var & -68180214 & \multicolumn{2}{|c|}{ S.D. dependent var } & $1.79 \mathrm{E}+11$ \\
\hline S.E. of regression & $1.71 \mathrm{E}+11$ & \multicolumn{2}{|c|}{ Sum squared resid } & $4.64 \mathrm{E}+24$ \\
\hline J-statistic & 9.900433 & \multicolumn{2}{|c|}{ Instrument rank } & 12 \\
\hline Prob(J-statistic) & 0.358606 & & & \\
\hline
\end{tabular}

